ORIGINAL ARTICLE

\title{
Chlamydia trachomatis prevalence in men in the mid-west of Ireland
}

\author{
J Powell, C O'Connor, M Ó'hĺarlaithe, J Saunders, J de Freitas
}

See end of article for authors' affiliations .....................

Correspondence to: Mr J Powell, Department of Microbiology, MidWestern Regional Hospital, Dooradoyle, Limerick City, Ireland; ipowell@mwhb.ie

Accepted for publication 19 February 2004
Sex Transm Infect 2004;80:349-353. doi: 10.1136/sti.2003.008615

Objectives: To estimate the prevalence of chlamydia infection in young men in the Mid-Western Health Board Region of Ireland, and to determine risk factors for its acquisition.

Methods: Consecutive men attending orthopaedic clinics (OPD), and a university sports arena (UL) were recruited to a chlamydia prevalence study. All men aged 17-35 who had been sexually active and had not passed urine in the last hour were eligible. Information about chlamydia was given, informed consent obtained, and a self administered questionnaire was completed. A first void urine (FVU) was collected and tested by ligase chain reaction (LCR).

Results: $82 \%(207 / 252)$ of men from OPD, and 60\% (186/310) from UL participated. 6.3\% (13/207) from the OPD and 5.4\% (10/186) from UL tested LCR positive, giving an overall prevalence of $5.9 \%(23)$ 393). Proved risk factors for chlamydial positivity were: (1) more than one sexual partner in previous 6 months, (2) more than eight lifetime sexual partners, (3) current symptoms (dysuria or discharge). No statistical significance was found for age, condom use, smoking, days since last sexual intercourse and previous GUM clinic attendance. No statistically significant difference to cost effective prevalence of $6 \%$ was shown.

Conclusions: A 5.9\% prevalence of Chlamydia trachomatis was found which is cost effective to screen and treat. Non-invasive screening of men in the community was possible. Numbers of sexual partners and current symptoms were significant risk factors. Since only $25 \%$ of men in this laboratory were diagnosed with chlamydia outside the GUM clinic, compared with $59 \%$ of women, it is important that community screening of men is promoted.
$\mathrm{H}$ ealthcare providers often see chlamydial infection, like other STDs, as a women's health issue, as its complications in women are well known. As a result, men are relatively ignorant about its transmission, prevention, and control. ${ }^{1}$ No doubt this is partially because $50 \%-70 \%$ of infections in women ${ }^{2}$ and $40 \%-50 \%$ of those in men $^{3}$ are clinically silent. Research in the United States and Sweden has shown that detection and treatment of asymptomatic infections in women result in a reduction of complications. ${ }^{45}$

The number of diagnoses of chlamydia has been consistently higher in women than men, by more than $30 \%{ }^{6}$ In the Limerick regional laboratory in the 12 months up to October 2003, almost twice as many women (264/3851) as men (149/ 1496) were diagnosed positive. Over $75 \%$ of chlamydia positive men (112/149) were patients in the GUM clinic, compared to $41 \%$ of women (109/264). Screening men for chlamydial infection, especially those without symptoms has been considered problematic, ${ }^{1}$ mainly because men are less likely than women to attend healthcare settings. ${ }^{7}$ In the past, screening asymptomatic men was further hampered by the necessity for invasive sampling techniques. ${ }^{1}$ The development of nucleic acid amplification tests (NAATs) using urine offers great potential for the screening of men, an important reservoir of infection for women, in epidemiological settings.

Cost effectiveness analyses have shown that screening becomes cost effective at prevalence ranging from $2 \%$ to $6 \%{ }^{8-13}$ Screening outside of GUM clinics needs evaluating if a significant impact is to be made. ${ }^{14}$ Chlamydia trachomatis fits the general prerequisites for disease prevention by screening: The disease is prevalent in the community, consequences of infection are severe, and no harm can come to the patient by taking part. The test is highly sensitive and specific, relatively cheap and has a rapid turnaround. Treatment is available, and there is a positive outcome for patients, partners and the community.

This cross sectional study was set up to estimate the prevalence of chlamydia infection in young men in the MidWestern Health Board region of Ireland, and to determine risk factors for acquisition of the infection.

\section{SUBJECTS AND METHODS}

\section{Study cohorts}

Two populations were chosen, young men attending orthopaedic outpatient clinics (OPD) in the Mid-Western Regional Hospital, Limerick, and a mixture of students and general public attending sports facilities in the University of Limerick (UL). Cohorts were recruited intermittently but consecutively while researchers were in attendance. Men aged 17-35 who had ever been sexually active in their lifetimes and had not passed urine in the past hour were eligible for inclusion. Men were recruited from September 2002 to December 2002 in UL, and September 2002 to June 2003 in OPD. This study aimed to estimate an expected prevalence of $3.5 \%$ (SD 2.5\%) $(\mathrm{n}=208$, UL and OPD $)$.

\section{Measures}

Demographic details and risk factors were obtained from a self administered, confidential questionnaire. Informed consent was obtained. Contact details of patients were requested and a first pass urine specimen was collected. Questionnaires consent forms, and specimen containers were bar coded and retained. The researchers' contact details were given to the participants on an information sheet, which contained the

Abbreviations: FVU, first void urine; LCR, ligase chain reaction; NAATs, nucleic acid amplification tests 
same bar code number for identification purposes. Urine specimens were chilled immediately, frozen to $-20^{\circ} \mathrm{C}$ within 4 hours, and individually analysed within 3 days by ligase chain reaction (LCR) assays (Abbott) as per manufacturer's instructions. All positive urines were confirmed by repeat LCR. Those who had positive tests were informed by mobile phone and email. An emergency appointment at the GU-STD clinic was given for patient and partner(s).

\section{Statistical analysis}

Statistical data were analysed by using SPSS V1l. Means (age, number sexual partners, etc) were compared using $t$ test. $\chi^{2}$ tests were used to compare prevalence for each category variable. The overall prevalence was compared to prevalence of $2 \%,{ }^{10} 3.9 \%,{ }^{11}$ and $6 \%{ }^{12}{ }^{13}$ (published cost effective prevalence) by calculating the "z scores"; 95\% confidence was regarded as significant for the study.

\section{Ethical approval}

Ethical approvals were received from the Mid-Western regional hospital ethics committee and the University of Limerick research ethics board.

\section{RESULTS}

\section{Study cohort}

In all, 186 men were recruited from UL (60\% acceptance), and 207 men from OPD (82\% acceptance). Table 1 displays the demographics of all participants in both cohorts and those who tested chlamydia positive.

\section{Measures}

There was no significant difference between the two cohorts for: (a) current symptoms (discharge or burning sensation while urinating) (UL 4\%, OPD 5\%), difference: $1 \%$ (95\% CI: -3 to 5); (b) previous symptoms (UL $31 \%$, OPD $21 \%$ ), difference: $10 \%$ (95\% CI: -5 to 9.5 ); (c) previous STD clinic attendance (UL 6\%, OPD 7\%), difference: $1 \%$ (95\% CI: -8 to 10); (d) mean lifetime sexual partners (UL 9.3, OPD 10.7), difference: 1.4 partners (95\% CI: -2.2 to 5.1 ); (e) mean days since last sexual intercourse (UL 44.4, OPD 53.0), difference 8.6 days ( $95 \%$ CI: -23.6 to 40.8 ).

There was a statistically significant difference found for the following factors: (a) mean sexual partners in the last 6 months (UL 2.3, OPD 1.7): difference 0.6 partners (95\% CI: -1.1 to -0.08 . $\mathrm{p}=0.023$ ); (b) age (UL 22.8, OPD 25.4 years): difference: 2.6 years (95\% CI: 1.75 to 3.5 . $p<0.0005$ ); (c) smokers (UL 26\%, OPD 38\%): difference $12 \%$ (95\% CI: 3 to $21 . \mathrm{p}=0.024$ ); (d) condom users (UL $78 \%$, OPD $56 \%$ ): difference $18 \%$ ( $95 \%$ CI: 12 to $32 . p=0.001)$.

\section{Prevalence}

The overall prevalence of Chlamydia trachomatis was 5.9\% (95\% CI: 3.6 to 8.2 ). The prevalence in UL was 5.4\% (95\% CI: 2.1 to 8.6 ), and OPD was $6.3 \%$ (95\% CI: 3.1 to 9.5). The difference of $0.9 \%$ ( $95 \% \mathrm{CI}:-3.7$ to 5.5 ) between the two cohorts was not statistically significant.

\section{Chlamydia positive}

Table 2 shows the demographic variables for chlamydia positive and negative men as a complete group.

The following risk factors were not found to be statistically significance for acquisition of chlamydia: (i) cohort studied $(p=0.83)$, (ii) age $(p=0.83)$, (iii) smoking $(p=0.24)$, (iv) condom use $(p=0.15)$, ( $v)$ previous symptoms $(p=0.15)$, (vi) previous STD clinic attendance $(\mathrm{p}=0.22)$, (vii) mean days since last sexual intercourse $(p=0.58)$.

Table 1 Characteristics of the study populations and the Chlamydia trachomatis positive populations

\begin{tabular}{|c|c|c|c|c|}
\hline & \multicolumn{2}{|l|}{ OPD } & \multicolumn{2}{|l|}{ UL } \\
\hline & Total $(n=207)$ & CT Pos (n = 13) & Total $(n=186)$ & CT Pos $(n=10)$ \\
\hline \multicolumn{5}{|l|}{ Age (years) } \\
\hline $17-20$ & $37(17 \%)$ & $2(15 \%)$ & $56(30 \%)$ & $4(40 \%)$ \\
\hline $21-24$ & $62(30 \%)$ & $3(23 \%)$ & $92(49 \%)$ & $4(40 \%)$ \\
\hline $25-29$ & $70(34 \%)$ & $6(46 \%)$ & 30 (16\%) & $2(20 \%)$ \\
\hline $30-35$ & $38(18 \%)$ & $2(15 \%)$ & $8(4 \%)$ & 0 \\
\hline \multicolumn{5}{|l|}{ Smoking } \\
\hline Yes & $74(38 \%)$ & $4(33 \%)$ & $45(26 \%)$ & $2(20 \%)$ \\
\hline Missing data & $19(10 \%$ of total $)$ & 0 & 14 (8\% of total) & 0 \\
\hline \multicolumn{5}{|l|}{ Condom use } \\
\hline Yes & $111(56 \%)$ & $8(62 \%)$ & $133(78 \%)$ & $6(60 \%)$ \\
\hline Missing data & 26 (13\% of total) & 0 & 15 (8\% of total) & 0 \\
\hline \multicolumn{5}{|l|}{ Symptoms } \\
\hline Ever & $42(21 \%)$ & $4(31 \%)$ & $53(31 \%)$ & $4(40 \%)$ \\
\hline Recent & $10(5 \%)$ & $3(23 \%)$ & $7(4 \%)$ & $2(20 \%)$ \\
\hline Missing data & 26 (13\% of total) & 0 & $17(9 \%$ of total) & 0 \\
\hline \multicolumn{5}{|l|}{ Last sexual intercourse } \\
\hline 1 Day & $29(15 \%)$ & $3(23 \%)$ & 21 (13\%) & $1(10 \%)$ \\
\hline 2-14 Days & $78(40 \%)$ & $6(46 \%)$ & $62(39 \%)$ & $5(50 \%)$ \\
\hline 15 Days to 1 month & $22(11 \%)$ & $1(8 \%)$ & $24(13 \%)$ & 0 \\
\hline 1-6 Months & $36(18 \%)$ & $3(23 \%)$ & $43(24 \%)$ & $4(40 \%)$ \\
\hline 1 Year & $9(5 \%)$ & 0 & $4(2 \%)$ & 0 \\
\hline$>1$ Year & $4(2 \%)$ & 0 & $4(2 \%)$ & 0 \\
\hline Missing data & 32 ( $16 \%$ of total) & 0 & 31 ( $21 \%$ of total) & 0 \\
\hline \multicolumn{5}{|l|}{ Aftended STD clinic } \\
\hline Yes & $14(7 \%)$ & 0 & $10(6 \%)$ & $2(20 \%)$ \\
\hline Missing data & 23 (11\% of total) & 0 & $18(10 \%)$ & 0 \\
\hline \multicolumn{5}{|l|}{6 Month sexual partners } \\
\hline$\leqslant 1$ & 124 (63\%) & $4(31 \%)$ & $87(47 \%)$ & $1(10 \%)$ \\
\hline$>1$ & $54(27 \%)$ & $9(69 \%)$ & $73(41 \%)$ & $9(90 \%)$ \\
\hline Missing data & 11 (6\% of total) & 0 & 26 (15\% of total) & 0 \\
\hline \multicolumn{5}{|l|}{ Lifetime sexual partners } \\
\hline$\leqslant 8$ & $98(50 \%)$ & $3(23 \%)$ & 97 (52\%) & $3(30 \%)$ \\
\hline$>8$ & $67(34 \%)$ & $10(77 \%)$ & $50(27 \%)$ & $7(70 \%)$ \\
\hline Missing data & 32 (16\% of total) & 0 & 39 (21\% of total) & 0 \\
\hline
\end{tabular}


Table 2 Univariate analysis of demographics and behavioural factors with chlamydial infection

\begin{tabular}{|c|c|c|c|}
\hline & \multirow{2}{*}{$\frac{\text { CT Pos }}{\text { No (\%) }}$} & \multirow{2}{*}{$\frac{\text { CT Neg }}{\text { No (\%) }}$} & \multirow[b]{2}{*}{$p$ Value } \\
\hline & & & \\
\hline Total & 23 & 370 & \\
\hline \multicolumn{4}{|l|}{ Location } \\
\hline OPD & $13(57 \%)$ & $194(52 \%)$ & 0.830 \\
\hline UL & $10(43 \%)$ & $176(48 \%$ & \\
\hline \multicolumn{4}{|l|}{ Age (years) } \\
\hline $17-20$ & $6(26 \%)$ & $87(24 \%)$ & \\
\hline $21-24$ & $7(30 \%)$ & $147(40 \%)$ & 0.827 \\
\hline $25-29$ & $8(35 \%)$ & $92(25 \%)$ & \\
\hline $30-35$ & $2(9 \%)$ & $44(12 \%)$ & \\
\hline \multicolumn{4}{|l|}{ Smoking } \\
\hline Yes & $6(26 \%)$ & $113(31 \%)$ & 0.244 \\
\hline Missing data & 0 & 33 & \\
\hline \multicolumn{4}{|l|}{ Condom use } \\
\hline Yes & $14(61 \%)$ & $230(62 \%)$ & 0.153 \\
\hline \multirow{2}{*}{\multicolumn{4}{|c|}{ Symptoms }} \\
\hline & & & \\
\hline Ever & $8(35 \%)$ & $87(24 \%)$ & 0.149 \\
\hline Recent & $5(22 \%)$ & $12(3 \%)$ & $<0.0005$ \\
\hline \multirow{2}{*}{\multicolumn{4}{|c|}{ Last sexual intercourse }} \\
\hline & & & \\
\hline 1-7 Days & $12(52 \%)$ & $142(53 \%)$ & 0.578 \\
\hline 8-14 Days & $3(13 \%)$ & 35 (13\%) & \\
\hline 15 Days to 1 month & $2(9 \%)$ & $29(11 \%)$ & \\
\hline 1-6 Months & $6(26 \%)$ & $49(18 \%)$ & \\
\hline 1 Year & 0 & $5(2 \%)$ & \\
\hline$>1$ Year & 0 & $8(3 \%)$ & \\
\hline Missing data & 0 & 102 & \\
\hline \multicolumn{4}{|l|}{ Aftended STD clinic } \\
\hline Yes & $2(9 \%)$ & $22(6 \%)$ & 0.223 \\
\hline Missing data & 0 & 41 & \\
\hline \multicolumn{4}{|l|}{6 Month sexual partners } \\
\hline$\leqslant 1$ & $5(22 \%)$ & $206(65 \%)$ & $<0.0005$ \\
\hline$>1$ & $18(78 \%)$ & 109 (35\%) & \\
\hline Missing data & 0 & 55 & \\
\hline \multicolumn{4}{|l|}{ Lifetime sexual partners } \\
\hline$\leqslant 8$ & $6(26 \%)$ & $189(65 \%)$ & \\
\hline$>8$ & $17(74 \%)$ & $100(35 \%)$ & $<0.0005$ \\
\hline Missing data & 0 & 81 & \\
\hline
\end{tabular}

There was, however, a statistically significant increased risk of acquiring infection found for the men from the study who had: (i) more than one sexual partner in the last 6 months $(p \leqslant 0.0005)$, (ii) more than eight sexual partners in their lifetime $(\mathrm{p} \leqslant 0.0005)$, (iii) current symptoms $(\mathrm{p} \leqslant 0.0005)$.

\section{Cost effectiveness}

Screening for Chlamydia trachomatis has been shown to be cost effective at $2 \%^{10} 3.9 \%{ }^{11}$ and $6 \% .{ }^{12}{ }^{13}$ Table 3 shows comparisons between our prevalence and the above prevalence by the use of " $\mathrm{z}$ " scores. There was no statistically significant difference from prevalence of $6 \%$ found in any group. For the total group there was a significant difference of $2 \%$ and $3.9 \%$ found.

\section{DISCUSSION}

This, to our knowledge, is the first time community screening of men has been undertaken in Ireland. The prevalence in this study of $5.4 \%$ in UL and $6.3 \%$ in OPD (overall $5.9 \%$ ) is on a par with a Danish study $(5.8 \%),{ }^{15}$ higher than UK studies $\left(1.2 \%^{16}\right.$ to $\left.2.2 \%^{17}{ }^{18}\right)$ though lower than a Canadian one (8\%). ${ }^{19}$ It should be noted that in the above studies with the exception of one, ${ }^{17}$ participants were recruited from registers and specimens were "home mailed." In this study all men were recruited on site.

A larger proportion of people were represented in the 1724 year age group in UL (79\%) than in OPD (48\%), while more than twice as many were represented in the 25-35 year age group in the OPD group. This age difference between the two groups was shown to be statistically significant. Only two

Table 3 Comparison of prevalence found with published cost effective prevalence. Only $p$ values of the significant figures are given

\begin{tabular}{llll}
\hline & \multicolumn{3}{l}{} \\
\cline { 2 - 4 } L scores & & \\
\hline UL $(5.4 \%)$ & $\mathbf{2 . 0 \%}$ Prevalence & $\mathbf{3 . 9 \%}$ Prevalence & $\mathbf{6 . 0 \%}$ Prevalence \\
OPD $(6.3 \%)$ & $3.31(p=0.001)$ & 1.06 & -0.03 \\
Total $(5.9 \%)$ & $4.42(p=0.0001)$ & 1.78 & 0.18 \\
\hline
\end{tabular}

OPD, outpatients department; UL, university sports arena. 
Chlamydia trachomatis positive men were found in the 3035 year age group. This is in contrast with recent London studies in which their highest prevalence was in $30-35^{20}$ and 25-34 year old men. ${ }^{21}$ No statistical significance was shown for age groups in this study.

The difference $(33 \%, p=0.024)$ between the two cohorts for smoking may be as a result of the UL sample being recruited from a sports arena. More use of condoms in this cohort $(15 \%, p=0.001)$ might be as a result of a lower age group, better sexual health education, or more partner change as reflected in the number of partners in the last 6 months, though it was not statistically significant. However, no statistical significance was shown for those who were infected for either of the above risk factors.

Current symptoms were found to be significant in predicting chlamydia infection $(p \leqslant 0.0005)$, even though only $22 \%$ of the positive participants reported recent symptoms. Interestingly, $3 \%$ of the negative participants indicated similarly, but no other infections were sought.

No statistical difference was found between the two groups or within the groups for chlamydial infection for any length of time since last sexual intercourse (see table 1 ). It is interesting to note that $26 \%(6 / 23)$ of patients who tested positive reported no sexual intercourse for a range of 6 weeks to 6 months $(42,42,48,60,60,180$ days $)$. This must indicate persistence of infection for at least this period in these men, though the frequency of prolonged infection is unknown, as no study has consistently evaluated men for more than 4 weeks of infection. ${ }^{22}$

Previous attendance at GUM clinics (OPD7\%, UL 6\%) were similar for the two cohorts, and were not different from the UK National Survey of Sexual Attitudes and Lifestyles (NATSSAL) which showed 7\% previous GUM attendance, while a north west London study of men in the community found $20 \%{ }^{20}$

In both cohorts, $10 \%$ had been monogamous in their lifetimes, and no chlamydia positive man was found in this group. More than one sexual partner in the last 6 months and greater than eight lifetime sexual partners were statistically significant $(p \leqslant 0.0005)$ for chlamydial infection.

\section{Cost effectiveness}

The most evidence available supports cost effectiveness for screening and treating in the community at $6 \%$ prevalence. ${ }^{12}{ }^{13}$ The figures here show that the prevalence is not significantly less than $6 \%$. This would indicate that screening and treating the men in the mid-west of Ireland aged between 17 and 35 years who have been sexually active in their lifetimes would be cost effective.

\section{Refusals}

Considering $25-35 \%$ of people generally refuse to engage in face to face interviews designed to investigate sexual attitudes and lifestyles, ${ }^{18}$ getting refusal rates for a study requiring a specimen as well as a questionnaire of 30\% (169/ $562)$ is acceptable. There was a greater refusal rate in UL $(40 \%, 124 / 310)$ than OPD $(18 \%, 45 / 252)$, but both rates compare well against refusal rates of $35^{21}$ to $71^{16} \%$ for postal surveys. Most non-participants did not give a reason (65\%, 110/169), with "not at risk" (51\%, 30/59) and "no time" $(39 \%, 23 / 59)$ being the main ones.

\section{Limitations}

The target size of 208 participants was very nearly achieved for both cohorts, and this sample size is less than most other studies cited. It may be possible that neither of the two study populations may be representative of all men aged 17-35 in the region. However, the number of chlamydia positive men in both cohorts was small $(n=10,13)$, so the even distribution of infection in the age groups may be unreliable.

Omissions from the questionnaire included recent antibiotic use, ethnic group, and sexual preference.

\section{Strengths}

This is the first community based chlamydia prevalence study in men performed in Ireland. Unlike a London study, ${ }^{21}$ the use of a non-invasive screening test in the community with molecular methods proved to be feasible. Of those who participated, over $99 \%$ made the decision to take part immediately, even though they were given the opportunity to take the information and return if they wished. Telephones proved to be the most popular (70\% mobile, $8 \%$ land line) and confidential means of contact, followed by email (32\%). All criteria for a good screening programme were found to be satisfied.

\section{CONCLUSION}

A $5.9 \%$ prevalence of Chlamydia trachomatis was found in 1735 year old men in the mid-west region of Ireland . The only risk factors of statistical significance found were (1) more than one sexual partner in the last 6 months, (2) more than eight lifetime partners, (3) current symptoms (discharge or burning sensation while urinating). Non-invasive screening of men in the community was shown to be feasible in the populations selected. Since only $25 \%$ (37/149) men in this laboratory were diagnosed with chlamydia from outside the GUM clinic, compared to $59 \%(155 / 264)$ of women, it is important that we continue to find new ways to identify these men, who represent a significant reservoir of infection for women.

\section{ACKNOWLEDGEMENTS}

The authors would like to thank the Mid-Western Health Board for providing the resources for the study, Denis Barron and the rest of the staff of the microbiology department of the Mid-Western Regional Hospital for their support, and David Mahedy and the staff of the University of Limerick Arena and the staff of the Mid-Western Regional Hospital orthopaedic outpatients department.

\section{CONTRIBUTORS}

JP carried out fieldwork, data collection, and laboratory analysis; JP and COC prepared the study design, carried out fieldwork and analysis, and prepared the paper; MOH carried out fieldwork; JS did statistical analysis; JdF was the guarantor of the study.

\section{Authors' affiliations}

J Powell, J de Freitas, Microbiology Department, Mid-Western Regional Hospital, Limerick, Ireland

C O'Connor, Department of GU-STD, Mid-Western Regional Hospital, Limerick, Ireland

M Ó'hlarlaithe, Department of Medicine, Mid-Western Regional Hospital, Limerick, Ireland

J Saunders, Department of Mathematics and Statistics, University of Limerick, Ireland

\section{REFERENCES}

1 Fenton KA. Screening men for Chlamydia trachomatis infection: have we fully explored the possibilities? Commun Dis Public Health 2000;3:86-9.

2 Peeling RW, Brunham RC. Chlamydiae as pathogens: new species and new issues. Emerg Inf Dis 1996;2:307-19.

3 Tait A, Hart CA. Chlamydia trachomatis in non-gonococcal urethritis patients and their heterosexual partners: routine testing by polymerase chain reaction. Sex Trans Infect 2002;78:286-8.

4 Scholes D, Stergachis A, Heidrick FE, et al. Prevention of pelvic inflammatory disease by screening for cervical chlamydia infection. N Engl J Med 1996;334:1362-6.

5 Kamwendo F, Forslin L, Bodin I, et al. Decreasing incidences of gonorrhoeaand chlamydia-associated acute pelvic inflammatory disease. A 25 year study from urban area of central Sweden. Sex Transm Dis 1996;23:384-91. 
6 Pimenta J, Fenton KA. Recent trends in Chlamydia trachomatis in the United Kingdom and the potential for national screening. Eurosurveillance 2000;9:81-4.

7 Tobin JM, Harindra V, Tucker $\amalg$. The future of chlamydia screening. Sex Transm Infect 2000;76:233-4.

8 Genc M, Ruusuvaara L, Mardh PA. An economic evaluation of screening for Chlamydia trachomatis in adolescent males. JAMA 1993;270:2057-64.

9 Marrazzo JM, Celum CL, Hillis SD, et al. Performance and cost-effectiveness of selective screening criteria for Chlamydia trachomatis infection in women. Implications for a national chlamydia control strategy. Sex Transm Dis 1997;24:131-41.

10 Howell MR, Quinn TC, Gaydos CA. Screening for Chlamydia trachomatis in asymptomatic women attending family planning clinics. A cost-effectiveness analysis of three strategies. Ann Intern Med 1998;128:277-84.

11 Paavonen J. Is screening for Chlamydia trachomatis infection cost effective? Genitourin Med 1997;73:103-4.

12 Mardh A. A cost-effectiveness analysis of screening and treating for Chlamydia trachomatis infection in asymptomatic women. Ann Intern Med 1996; 124(Pt 1):1-7.

13 Pavoneen J, Poulakkainen M, Paukku M, et al. Cost-benefit analysis of firstvoid urine Chlamydia trachomatis screening programme. Obstet Gynaecol 1998;92:292-8.

14 Stephenson JM. Screening for genital chlamydial infection. Br Med Bull 1998;54:891-902.
15 Anderson B, Olesen F, Møller JK, et al. Population-based strategies for outreach screening of urogenital Chlamydia trachomatis Infections: randomised, controlled trial. Sex Transm Infect 2002;185:252-8.

16 Rogstad KE, Bates SM, Partridge S, et al. The prevalence of Chlamydia trachomatis infection in male undergraduates: a postal survey. Sex Transm Infect 2001;77:111-13.

17 Aldeen T, Haghdoost A, Hay P. Urine based screening for asymptomatic/ undiagnosed genital chlamydial infection in young people visiting the accident and emergency department is feasible, acceptable, and can be epidemiologically helpful. Sex Transm Infect 2003;79:229-33.

18 Fenton KA, Johnson AM, McManus S, et al. Measuring sexual behaviour: methodological challenges in survey research. Sex Trans Infect 2001;77:84-92

19 Hodgins S, Peeling RW, Dery S, et al. The value of mass screening for chlamydia control in high prevalence communities. Sex Trans Infect 2002;78(suppl 1):i64-8.

20 Pierpoint T, Thomas B, Judd A. et al, Prevalence of Chlamydia trachomatis in young men in north west London. Sex Transm Infect, 2000;76:273-6.

21 Fenton KA, Korovessis C, Johnson AM, et al. Sexual behaviour in Britain Reported sexually transmitted infections and prevalent genital Chlamydia trachomatis infection. Lancet $2001 ; 358: 1851-9$

22 Golden MR, Schillinger JA, Markowitz L, et al. Duration of untreated genital infections with chlamydia trachomatis: a review of the literature. Sex Transm Dis 2000;27:329-37.

\section{Clinical Evidence - Call for contributors}

Clinical Evidence is a regularly updated evidence based journal available worldwide both as a paper version and on the internet. Clinical Evidence needs to recruit a number of new contributors. Contributors are health care professionals or epidemiologists with experience in evidence based medicine and the ability to write in a concise and structured way.

Currently, we are interested in finding contributors with an interest in the following clinical areas:

Altitude sickness; Autism; Basal cell carcinoma; Breast feeding; Carbon monoxide poisoning; Cervical cancer; Cystic fibrosis; Ectopic pregnancy; Grief/bereavement; Halitosis; Hodgkins disease; Infectious mononucleosis (glandular fever); Kidney stones; Malignant melanoma (metastatic); Mesothelioma; Myeloma; Ovarian cyst; Pancreatitis (acute); Pancreatitis (chronic); Polymyalgia rheumatica; Post-partum haemorrhage; Pulmonary embolism; Recurrent miscarriage; Repetitive strain injury; Scoliosis; Seasonal affective disorder; Squint; Systemic lupus erythematosus; Testicular cancer; Varicocele; Viral meningitis; Vitiligo However, we are always looking for others, so do not let this list discourage you.

Being a contributor involves:

- Appraising the results of literature searches (performed by our Information Specialists) to identify high quality evidence for inclusion in the journal.

- Writing to a highly structured template (about 2000-3000 words), using evidence from selected studies, within 6-8 weeks of receiving the literature search results.

- Working with Clinical Evidence Editors to ensure that the text meets rigorous epidemiological and style standards.

- Updating the text every eight months to incorporate new evidence.

- Expanding the topic to include new questions once every 12-18 months.

If you would like to become a contributor for Clinical Evidence or require more information about what this involves please send your contact details and a copy of your CV, clearly stating the clinical area you are interested in, to Claire Folkes (cfolkes@bmigroup.com).

\section{Call for peer reviewers}

Clinical Evidence also needs to recruit a number of new peer reviewers specifically with an interest in the clinical areas stated above, and also others related to general practice. Peer reviewers are health care professionals or epidemiologists with experience in evidence based medicine. As a peer reviewer you would be asked for your views on the clinical relevance, validity, and accessibility of specific topics within the journal, and their usefulness to the intended audience (international generalists and health care professionals, possibly with limited statistical knowledge). Topics are usually 2000-3000 words in length and we would ask you to review between 2-5 topics per year. The peer review process takes place throughout the year, and our turnaround time for each review is ideally 10-14 days.

If you are interested in becoming a peer reviewer for Clinical Evidence, please complete the peer review questionnaire at www.clinicalevidence.com or contact Claire Folkes(cfolkes@bmigroup.com). 